\title{
Fiqh Budaya dalam Perspektif Tarian Tayub pada Tradisi Sedekah Bumi
}

\author{
Maskur \\ Sekolah Tinggi Ilmu Agama Wali Sembilan Semarang \\ maskur2106128401@gmail.com
}

\begin{abstract}
Tayub dance is held as one of the things that must be held every the implementation of the earth alm tradition. Tayub dance in the tradition of alms in Plaosan Village, Cluwak district, regency is an interesting center to be studied, especially from the perspektif of cultural fiqh. The focus of research in this study is related to the study of cultural fiqh which views the tayub dance ritual in the tradition of almsgiving in the village of Plaosan, Cluwak district, Pati regency. The reseach metod in this research is qualitative which describes in detail the reseach focus. The results showes that tayub dance as a mandatory ritual of the earth alms tradition is an activity carried out as an expression of joy and a form of gratitude to God Almighty. Based on the study of cultural fiqh in tayub dance. Basically it sees an important part that the tradition of dancing is not somethings that is prohibited bs Islam as long as it does not cause deterioration and mislead the community. Thus it permissible todo so because it does not contradict religious law.
\end{abstract}

Keywords: tayub, alm earth, cultural fiqh

\begin{abstract}
Abstrak
Tari tayub diselenggarakan sebagai salah satu hal yang wajib diadakan setiap pelaksanaan tradisi sedekah bumi. Tari tayub merupakan center yang menarik untuk dikaji terutama dilihat dari kacamata fiqh budaya. Fokus penelitian dalam penelitian ini berkaitan dengan kajian fiqh budaya yang memandang ritual tarian tayub pada tradisi sedekah bumi di desa Plaosan, Kecamatan Cluwak Kabupaten Pati. Metode penelitian dalam penelitian ini yaitu penelitian kualitatif yang mendeskripsikan secara rinci dan mendalam fokus penelitian yang diteliti. Hasil penelitian melihat bahwa tarian tayub sebagai ritual wajib tradisi sedekah bumi merupakan kegiatan yang dilaksanakan sebagai ekspresi kegembiraan dan wujud syukur kepada Tuhan Yang Maha Esa. Berdasarkan kajian fiqh budaya dalam tarian Tayub pada dasarnya melihat bagian penting bahwa tradisi menari bukanlah hal yang dilarang oleh agama Islam selagi tidak menimbulkan kemudaratan dan menyesatkan masyarakat. Dengan demikian boleh dilakukan karena tidak bertentangan dengan syariat agama.
\end{abstract}

Kata Kunci : Tayub, sedekah bumi, fiqh budaya 



\section{Pendahuluan}

Masyarakat Jawa seperti diketahui adalah masyarakat yang memiliki kekayaan berbagai macam tradisi. Tradisi masyarakat nampak dari adanya berbagai selamatan Page| 69ang mengiringi proses kehidupan maupun perayaan hari besar keagamaan. Selamatan dalam pandangan orang Jawa memiliki nilai keagamaan dan nilai sosial yang dapat memupuk rasa solidaritas tinggi dalam kehidupan masyarakat yaitu berupa kerukunan, kebersamaan dan keharmonisan. Diadakannya selamatan tersebut akan menimbulkan perasaan kuat bahwa semua warga memiliki kedudukan yang sama dalam masyarakat. Pelaksanaan sedekah bumi sangat lazim diselenggarakan di Pulau Jawa, namun umumnya dilakukan berbeda-beda antara daerah yang satu dengan dengan daerah lainnya. ${ }^{1}$

Masyarakat Jawa biasanya dikenal sebagai masyarakat yang memiliki beragam jenis tradisi budaya. Tradisi tersebut dilakukan sepanjang kehidupan masyarakat dari pernikahan, kehamilan, kelahiran bahkan hingga kematian.

Tradisi atau upacara masyarakat Jawa pada prinsipnya berpedoman teguh pada dua aspek. Aspek pertama didasarkan pada kepercayaan yang berbau religius dan mistis. Salah satunya adalah ritual sedekah bumi yang dianggap masih berbau hal mistis. ${ }^{2}$ Kedua, pada aspek yang menjunjung tinggi derajat hidup masyarakat. Pandangan hidup diyakini selalu dikaitkan pada sesuatu yang Agung yaitu pada Tuhan yang bersifat mistis, rohaniah dan magis.

Upacara tradisional adat Jawa dilakukan demi tujuan yang utama yaitu tercapainya kebahagiaan hidup baik lahir maupun batin. Diadakannya upacara tradisional tersebut, dianggap akan memenuhi kebutuhan spiritual dan ingat kepada sang Pencipta. Kehidupan keagamaan bagi orang Jawa diyakini dari ajaran agama yang dikaitkan dengan budaya lokal. ${ }^{3}$ Dapat diketahui bahwa masyarakat Jawa memiliki orientasi kehidupan pada aspek-aspek luhur wariskan nenek Moyangnya.

\footnotetext{
1 Mohammad Thoriqul Huda, Harmoni Sosial Dalam Tradisi Sedekah Bumi Masyarakat Desa Pancur Bojonegoro, Religio, 7 (2017), 267-96 <jurnalfuf.uinsby.ac.id/index.php/religio/article/view/753\%0D>.hlm, 271

${ }^{2}$ Anggun sisweda, Nilai Pendidikan Islam Dalam Tradisi Sedekah Bumi (Studi Kasus Di Dusun Melati Desa Olak-Olak Kubu Kecamatan Kubu Kabupaten Kubu Raya Tahun 2019)', JRTIE, 3 (2020).hlm 112

3 Ubbadul Adzkiya and Anas Rohman, "Sacred Values Of Cows I n Kudus Society's View" 140, no. ISCoGI 2017 (2019): 72-75.
} 
Tradisi masyarakat Jawa yang tetap eksis sampai saat ini adalah diadakannya tradisi sedekah bumi. Tradisi tersebut merupakan eksistensi adanya kearifan lokal dalam bentuk tradisi atau upacara dengan wujud komunikasi antara manusia dengan lingkungan tempat tinggalnya. Hal yang membedakan tradisi sedekah bumi ini umunya selain penyebutan istilah yang berbeda beda di setiap daerah juga ritual yang wajib untuk dilakukan. ${ }^{4}$

Pelaksanaan tradisi sedekah bumi umumnya diselenggarakan satu kali dalam satu tahun. ${ }^{5}$ Hal tersebut dilaksanakan untuk tetap menjaga keserasian hubungan antara individu dengan alam ataupun dengan leluhurnya. Sedekah bumi adalah bentuk ritual adat yang memiliki makna sebagai rasa syukur manusia terhadap sang pencipta karena telah memberikan limpahan rezeki melalui berbagai hal diperoleh masyarakat terutama limpahan hasil bumi dsn tanah yang subur. ${ }^{6}$ Upacara sedekah bumi merupakan upacara yang sangat dinantikan oleh semua kalangan masyarakat. Hal ini karena sedekah bumi dianggap memiliki manfaat yang besar bagi masyarakat. Tradisi sedekah bumi ini sebagian besar dilakukan oleh masyarakat yang memiliki pekerjaan sebagai petani, dengan dilaksanakannya upacara tersebut diharapkan dapat meningkatkan hasil panen dan memberikan kesejahteraan bagi masyarakat.

Tradisi sedekah bumi dilaksanakan juga dengan alasan untuk menjaga hubungan yang harmonis dan selaras antara masyarakat dengan alam dan dengan leluhurnya. Tradisi ini pula dilaksanakan sebagai wujud rasa syukur masyarakat khususnya oleh para petani kepada Allah SWT karena hasil panen yang sangat melimpah. Sedekah bumi tetap dilaksanakan di beberapa wilayah di Jawa Tengah, salah satunya di desa Plaosan Kecamatan Cluwak Pati. Salah satu ritual yang menarik untuk dikaji adalah adanya ritual tarian tayub yang mengiringi setiap tradisi sedekah bumi dilaksanakan.

\footnotetext{
${ }^{4}$ R. Atang Supriatna, Menguak Realitas Praktik Sedekah Bumi di Desa Ciasmara Kecamatan Pamijahan Kabupaten Bogor, Wahana, 2 (2020)., hlm 46.

${ }^{5}$ Sabty - Pinihanti, Penanaman Rasa Syukur Melui Tradisi Sedekah Bumi di Desa Tegalarum, Demak:

Kajian Indigenous Psikologi, Pl', Dinamika Sosial Budaya, 22 (2020

$<$ https://journals.usm.ac.id/index.php/jdsb/article/view/2909/1864>.hlm 106

${ }^{6}$ Mohammad Thoriqul Huda, Harmoni Sosial Dalam Tradisi Sedekah Bumi Masyarakat Desa Pancur Bojonegoro, Religió: Jurnal Studi Agama-Agama, $7.2 \quad$ (2017) <https://doi.org/10.15642/religio.v7i2.753>.hlm. 271
} 
Tayub adalah tari yang bersifat tradisional dan masih sangat eksis baik di Jawa Timur mupun Jawa tengah. Termasuk di desa Plaosan yang menjadi ritual wajib dalam tradisi sedekah bumi. Tayub menjelma sebagai tarian yang diadakan sebagai wujud syukur atas limpahan berkah dan rezeki yang diberikan sang Khalik. Tayub diadakan dalam rangkaian ritual sedekah bumi di lingkungan masyarakat pedesaan dan dinggap sebagai lambang kesuburan, sehingga diharapkan dapat mempengaruhi kesuburan tanah pertanian. ${ }^{7}$

Adanya pelembagaan tari tayub masih berfungsi sebagai pelembagaan ritual khususnya di lingkungan pedesaan Jawa, terutama berfungsi untuk kesuburan tanah pertanian. Pelembagaan simbolis itu diwujudkan dalam hubungan antara penari wanita dan penari laki-laki. Penari tayub disebut dengan "ledhek" dan penonton laki-laki yang ikut menari disebut "pengibing". Tari tayub ini masih sering dilakukan bahkan menjadi hal yang wajib dalam upacara sedekah bumi. Tari Tayub pada dasarnya mengalami proses perubahan atau perkembangan sesuai dengan tuntutan peradaban masyarakat. ${ }^{8}$ Tari tayub diselenggarakan sebagai salah satu hal yang wajib diadakan setiap kali tradisi sedekah bumi dilaksanakan. Selain sebagai rasa syukur karena panennya berhasil, juga memohon keberhasilan selanjutnya. Berdasarkan observasi awal di desa Plaosan terkait ritual tari tayub dalam pelaksanaan sedekah bumi di desa Plaosan, kecamatan Cluwak Kabupaten Pati dapat dilihat bahwa tarian tayub menjadi center yang menarik untuk dikaji terutama dari kajian Fiqh budaya. Hal ini tentu melihat ilmu fikih yang bersifat dinamis, elastic dan responsif terhadap kemaslahatan umat ${ }^{9}$ yang mampu digunakan sebagai pedoman kehidupan masyarakat.

Berdasarkan perspektif figh budaya akan banyak hal yang bisa dikaji terutama berkaitan dengan bagaimana keberadaan tarian tayub dari perspektif budaya dan pemahaman agama tentang pembolehan ritual tari diadakan dalam tradisi masyarakat.

Adanya latar belakang tersebut memicu peneliti untuk melakukan penelitian berkaitan dengan Fiqh Budaya dalam Tarian Tayub Pada Tradisi Sedekah Bumi di desa Plaosan, kecamatan Cluwak Kabupaten Pati. Adapun fokus penelitian ini mengacu pada

\footnotetext{
${ }^{7}$ Sumandiyo Hadi, Sosiologi Tari. Yogyakarta: Pustaka, 2007, hlm.12-13

${ }^{8}$ suharji, Tari Tayub Sebagai Sarana Upacara Ritual di Desa Wonosoco Kecamatan Undaan Kudus, Acintya, 6 (2017) <https://jurnal.isi-ska.ac.id/index.php/acintya/about/editorialTeam\%0D>.hlm 59

${ }^{9}$ Sumarjoko, Hidayatun Ulfa, Kaidah Fiqh Bidang Mu'amalah Mazhab Syafi'i (Kajian Teoritis dan Praktik serta Kehujjahannya), Iqtisad, 6 (2019) $<$ https://publikasiilmiah.unwahas.ac.id/index.php/IQTISAD/article/view/2718/2678 > , hlm.35
} 
kajian fiqh budaya yang memandang ritual tarian tayub pada tradisi sedekah bumi di desa Plaosan, Kecamatan Cluwak Kabupaten Pati.

\section{Metode Penelitian}

Penelitian ini memakai pendekatan kualitatif dengan menggali dan mengumpulkan data bukan berupa deskripsi kata yang diperoleh dari hasil wawancara, catatan lapangan maupun dokumen pendukung lainnya. Tujuan penelitian kualitatif ini adalah untuk menggambarkan realita sesungguhnya dibalik peristiwa yang terjadi secara mendalam dan rinci. Penggunaan pendekatan kualitatif dalam penelitian ini dilakukan dengan mengkaitkan antara realita di lapangan dengan teori yang berlaku terutama menggunakan metode deskriptif. Penelitian deskriptif bertujuan untuk memberikan deskripsi serta gambaran tentang suatu keadaan secara nyata dan objektif. ${ }^{10}$ Kualitatif merupakan metode penelitian naturalistik karena penelitiannya dilakukan secara alamiah mengikuti kondisi yang sebenarnya.

Subjek dalam penelitian ini adalah tokoh agama, kepala desa, tokoh masyarakat, penari Tayub dan sesepuh desa yang dipercayai dalam tradisi sedekah bumi di desa Plaosan, kecamatan Cluwak Kabupaten Pati. Sumber data yang utama dalam penelitian ini yakni sumber data primer maupun sekunder. Sumber data sekunder berarti dari orang kedua yang memahami kondisi lapangan, atau bisa pula dari dari dokumen-dokumen yang diperlukan dalam penelitian ini terutama berkaitan dengan penyelenggaraan tradisi sedekah bumi. Adapun data primer dari orang atau dokumen langsung dari lapangan. Kegiatan observasi dilakukan dengan melakukan pengamatan pelaksanaan tradisi sedekah bumi di desa Plaosan kecamatan Cluwak Kabupaten Pati.

Untuk memperoleh data secara lengkap, teknik pengumpulan data dilakukan melalui wawancara, observasi dan dokumentasi. Teknik wawancara digunakan untuk menjawab permasalahan berkaitan dengan perkembangan ritual tarian tayub di desa Plaosan, Kecamatan Cluwak Kabupaten Pati.

\footnotetext{
${ }^{10}$ Fitria Martanti, "PERAN FURU KELAS DALAM MEMBERIKAN LAYANAN BIMBINGAN DAN KONSELING DI SDN WATUAJI 01 KABUPATEN JEPARA," Magistra 6 (2015). hlm 27
} 
Teknik observasi dilakukan dengan melakukan pengamatan langsung dalam kegiatan sedekah bumi dan ritual-ritual yang dilakukan. Dengan observasi akan dapat diperoleh data yang lengkap terkait dengan permasalahan dalam penelitian.Ke giatan observasi ini diarahkan untuk dapat melihat fasilitas maupun penyelenggaraan pendidikan di lokasi penelitian, sehingga dapat diketahui gambaran secara rinci terkait pertunjukkan tarian tayub dalam tradisi sedekah bumi di desa Plaosan, Kecamatan Cluwak Kabupaten Pati.

Teknik dokumentasi digunakan untuk mengumpulkan berbagai dokumen, peraturan, dan tulisan ilmiah lainnya yang berkaitan dengan masalah penelitian. Dokumentasi ini akan menggali data-data sekunder yang dibutuhkan untuk mendeskripsikan fokus penelitian. Studi dokumen diperlukan untuk melihat tinjauan fiqh budaya yang nampak dalam perkembangan ritual tarian tayub pada tradisi sedekah bumi di desa Plaosan, Kecamatan Cluwak Kabupaten Pati.

Analisis data dalam penelitian ini berupaya mencari, menata dan merumuskan data secara sistematis berdasarkan catatan hasil dokumentasi, observasi, maupun hasil wawancara. Hal ini dilakukan dengan tujuan untuk memperoleh dan mengembangkan pemahaman peneliti tentang kasus yang diteliti dan menyajikannya sebagai temuan hasil peselitian. Analisis juga perlu dilanjutkan untuk dapat meningkatkan pemahaman terhadap data yang diperoleh di lapangan. Data yang telah terkumpul dengan menggunakan metode deskriptif kualitatif kemudian dianalisis dengan langkahlangkah: mengkaji dan menelaah seluruh data yang terkumpul dari berbagai sumber, melakukan reduksi data dengan jalan abstraksi yaitu usaha membuat ringkasan atau rangkuman inti, proses dan pernyataan-pernyataan yang perlu. Melakukan penyusunan data dalam satuan-satuan atau mengorganisasikan pokok-pokok pikiran tersebut dengan cara cakupan fokus penelitian dan mengujikannuya dengan deskriptif. pemeriksaan keabsahan data atau memberi makna hasil penelitian dengan cara menghubungkan teori, langkah terakhir yaitu menarik sebuah simpulan.

\section{Hasil penelitian dan pembahasan}

Tradisi sedekah bumi merupakan manifestasi ritual tradisional masyarakat Jawa yang berlangsung secara turun-temurun dari leluhur atau nenek moyang. Secara garis 
besar berdasarkan hasil penelitian di Desa Plaosan dapat diketahui bahwa sedekah bumi tidak diketahui dari kapan dilaksanakan karena memang tradisi ritual yang sudah turun temurun dan masyarakat yang melaksanakan tradisi dari nenek moyang sebelumnya. Secara nyata beberapa tokoh agama, tokoh masyarakat juga memberikan keterangan bahwa sedekah bumi ini tidak tahu kapan acara ini dilaksanakan pertama kali karena tidak ada bukti secara tertulis yang menjelaskan sedekah bumi dilaksanakan untuk pertama kali.

Menurut penuturan Kuslan selaku kepala Desa juga menyebutkan bahwa tidak ada acuan kapan pasti pertama kali dilaksanakan tradisi sedekah bumi dilaksanakan. Hanya saja berdasarkan cerita para tetua diketahui bahwa tradisi ini kemungkinan dilaksanakan pertama kali semenjak penjajahan Jepang. Yang menarik adalah tradisi ini tetap dilaksanakan sampai sekarang meski di tengah masyarakat yang sudah tergolong masyarakat maju. Melihat perkembangan masyarakat desa Plaosan yang cukup maju merupakan bentuk inovasi masyarakat dan diyakini karena kemurahan Tuhan berkat dilaksanakan tradisis sedekah bumi ini. Inovasi dalam suatu masyarakat tersebut umumnya karena adanya faktor-faktor pendorong adanya suatu inovasi. ${ }^{11}$

Upacara sedekah bumi, umumnya memang dilakukan oleh masyarakat yang memiliki profesi sebagai petani, akan tetapi tidak menutup kemungkinan semua masyarakat terlibat dalam tradisi tersebut. Hal tersebut diketahui berdasarkan hasil wawancara dengan salah satu Tokoh masyarakat yakni bapak Djayusman yang menyatakan bahwa seluruh masyarakat mengikuti tradisi tersebut dan biasanya desa akan membentuk panitia pelaksana sebelum sedekah bumi dilaksanakan. Dalam pembentukan kepanitian biasanya dilaksanakan melalui musyawarah desa yang diwakilkan dari masing-masing RT dan RW. Hal-hal yang dikaji dalam musyawarah yakni mengenai kapan pelaksanaan sedekah bumi dilaksanakan yakni setiap Rabu Pahing di Bulan Apit atau bulan Syawal melihat kalender yang disesuiakan dengan syarat dilaksanakan sedekah bumi yaitu pada Rabu Pahing.

\footnotetext{
11 fitria martanti, "EVALUASI IMPLEMENTASI PROGRAM PENGEMBANGAN USAHA AGRIBISNIS PERDESAAN SEBAGAI UPAYA PEMBERDAYAAN MASYARAKAT MISKIN," Journal of Economic Education 1 (2012). hlm 98
} 
Berdasarkan pandangan sebagian masyarakat Jawa terutama bagi para petani, tradisi tahunan sedekah bumi sebenarnya bukan hanya dianggap rutinitas belaka, akan tetapi mempunyai makna yang lebih dari itu, yakni sebagai bentuk syukur kepada Tuhan sehingga dalam pelaksanaan tradisi sedekah bumi ada acara manganan atau bancaan di punden. Manfaat yang dirasakan dengan sedekah bumi adalah keyakinan bisa berhasil, misal petani bisa memperoleh panen yang maksimal. Hal itu seirama dengan apa yang dijelaskan oleh Munasir selaku tokoh Agama di desa Palosan.

Pelaksanaan tradisi sedekah bumi dilaksanakan dengan berbagai tahapan kegiatan. Kegiatan pertama yakni tahap persiapan tradisi dilaksanakan. Tahap persiapan dilakukan dengan membentuk panitia kegiatan, yang umumnya diwakili dari masing-masing dukuh. Ada 9 dukuh yang ada di desa Plaosan dan semuanya aktif dalam pelaksanaan tradisi sedekah bumi. Adapun sebelum kegiatan sedekah bumi juga dilaksanakan kegiatan selamatan yang umumnya dilakukan dengan doa bersama. Doa bersama ini bertujuan agar pelaksanaan tradisi sedekah bumi dapat berjalan dengan lancar dan sesuai dengan harapan semua masyarakat.

Tahap selanjutnya adalah tahap pelaksanaan sedekah bumi yang umumnya dilaksanakan dengan kegiatan "manganan" di punden desa. Kegiatan "manganan" sebenarnya layaknya selamatan bersama hanya saja dilaksanakan di punden sebagai bentuk menghargai para leluhur desa atas segala jasa-jasanya dalam membangun dan mengembangkan desa Plaosan hingga saat ini.

Selain kegiatan manganan sebagi bentuk syukur kepada Allah SWT, juga ada tradisi "arak-arakan" yang dilakukan dengan berkeliling desa untuk memperlihatkan hasil bumi yang diperoleh selama satu tahun. Kegiatan "arak-arakan" tersebut dilakukan dengan mengusung "ancak" untuk menampung berbagai hasil bumi. "Ancak" tersebut dibuat bervariasi menyesuaikan kemampuan masyarakat dalam membuat tempat untuk mengusung hasil humi. Hasil bumi yang telah diarak atau diiring ke seluruh desa lantas diserahkan ke balai kelurahahan dan diterima oleh kepala Desa. Pertunjukkan ketoprak juga menjadi pelengkap tradisi sedekah bumi yang diselenggarakan di setiap tahunnya.

Banyak nilai-nilai yang tersirat maupun tersurat dalam tradisi sedekah bumi yakni sebagai ungkapan syukur kepada Allah SWT. Nilai syukur nampak dari pelaksanaan tradisi sedekah bumi yang juga dilaksanakan dengan selamatan, doa 
bersama dan pemberian sedekah bagi yang tidak mampu. Nilai nilai lain yang terkandung dalam tradisi sedekah bumi adalah kebersamaan dan gotong royong. Hal ini karena tradisi sedekah bumi tidak akan terlaksana apabila tidak ada kerjasama dan gotong royong dalam melaksanakan tradisi tersebut.

Pelaksanaan sedekah bumi identik dengan Tarian Tayub yang dianggap wajib dalam ritual sedekah bumi. Memang tidak semua dukuh di desa Plaosan melaksanakan ritual tarian Tayub akan tetapi syarat wajib harus terpenuhi dengan mempersyaratkan harus dipertunjukkan Tarian Tayub dengan minimal 3 penari untuk menari dalam pelaksanaan tradisi sedekah bumi. Pelaksaaan tradisi sedekah bumi belum lengkap bila belum mengadakan pertunjukan Tari Tayub dengan demikian pertunjukkan Tarian tayub memiliki korelasi karena tanpa adanya pertunjukkan Tayub, tradisi sedekah bumi belum dianggap sempurna dilaksanakan.

Pelaksanaan pertunjukkan Tari Tayub ini secara nyata juga mengikuti perkembangan masyarakat. Berdasarkan pemaparan dari kepala Desa dapat diketahui bahwa awal mula dilaksanakan pertunjukan Tayub juga dibarengai dengan adanya kegiatan minum-minuman keras. Dengan berkembangan pemahaman agama yang semakin baik di kalangan masyarakat, maka kegiatan tersebut sudah tidak dilaksnakan karena melanggar ajaran agama terutama agama Islam.

Perkembangan lain yang nampak adalah pada pakaian yang dikenakan penari, bila dulu pada awal pelaksanaan menggunakan kemben sekarang lebih menyesuaikan dengan pemahaman masyarakat tentang kesopanan sehingga pakaian juga lebih tertutup meski secara gerakan memang ada pakem yang dipertahankan. Dengan demikian selain ada perkembangan pemahaman masyarakat tentang agama juga ada nilai pendidikan masyarakat yang berkembang. Salah satu nilai yang terkandung dalam penyelenggaraan tarian Tayub juga berakar dari adanya karakter cinta terhadap warisan leluhur yang melekat dalam setiap kegiatan masyarakat desa Plaosan. Ini merupakan bentuk character building yang ada di masyarakat. Character according to language means habit, whereas according to terms, character is a system of beliefs and habits that direct the actions of an individual. ${ }^{12}$ Dengan adanya pembiasaan dan pelestarian tradisi akan menimbulkan kecintaan masyarakat sehingga akan dapat menumbuhkan menjadi suatu budaya yang melekat dalam tradisi masyarakat.

\footnotetext{
12 fitria martanti, "INTERGRATION OF ASWAJA TEACHING: CONCEPT OF STRENGTHENING CHARACTER EDUCATION IN COLLEGE," n.d.
} 
Penari Tayub yang lebih dikenal dengan istilah "ledhek menjadi bagian penting dalam pelaksanaan tradisi sedekah bumi. Memahami bahwa perannya cukup penting dalam pelaksanaan tradisi sedekah bumi dilaksanakan dengan sungguh-sungguh agar tidak terjadi kesalahan selama pertunjukkan. Berdasarkan hasil observasi dan wawancara dengan penari, untuk mempersiapkan diri mempertunjukkan tarian Tayub biasanya dilakukan dengan rutin melaksanakan latihan sehingga tidak ada gerakan yang terlupa atau terlewat. Dengan melakukan kerjasama dengan penari lainnya dan dengan tokoh masyarakat kegiatan tersebut dapat dilaksanakan secara turun temurun dan dapat dilestarikan hingga sekarang.

Kajian Figh Budaya dalam Tarian Tayub pada dasarnya melihat bagian penting bahwa tradisi menari bukanlah hal yang dilarang oleh agama Islam, hal tersebut sama dengan apa yang dijelaskan oleh Imam al-Ghazali salah satu ulama figh yang memandang hukum tarian. Beliau menyebutkan bahwa menari adalah sebuah aktivitas yang biasa dilakukan secara alamiah sebagai cara untuk menghibur diri atau mencari kebahagiaan dan meluapkan ekspresi kesenangan atau kegembiraan. Agama Islam secara nyata tidak mengharamkan seseorang untuk menggerakkan seluruh anggota badan, baik itu kaki, tangan perut dan anggota tubuh lainnya, bahkan semua perbuatan itu akan muncul secara alamiah dan kadang tidak disadari manusia. Apabila menari itu dilarang (haram), tentu Rasulullah Saw akan melarang 'Aisyah melakukan hal yang sifatnya lahwi (menari). Sebagaimana diriwayatkan oleh Imam Bukhari dari 'Aisyah:

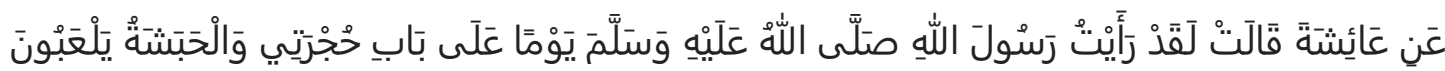

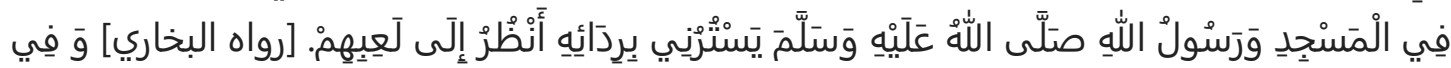

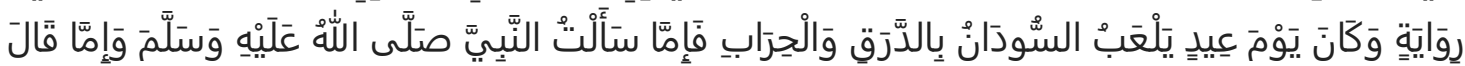

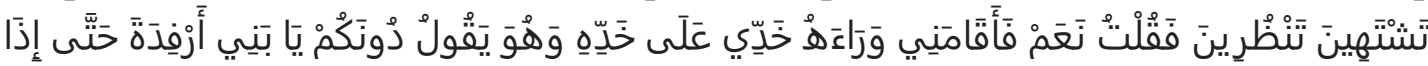

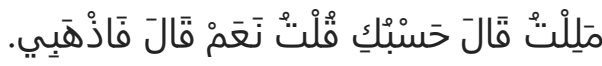

Artinya: "Diriwayatkan dari Aisyah, beliau berkata: Sebenarnya saya pernah melihat Rasulullah saw pada suatu hari (berdiri) di pintu kamarku, sementara orang-orang Habsyi sedang melakukan pertunjukan di masjid. Rasulullah menutupi saya dengan selendangnya sambil memperhatikan (menonton) permainan mereka." [HR. al-Bukhari] Dalam suatu riwayat lain: "Adalah hari itu Hari Raya, dimana orang-orang hitam (Habsyi) itu sedang bermain-main dengan perisai dan tombak. Adakala saya bertanya (sesuatu) kepada Rasulullah SAW dan adakala beliau bertanya: "Anda suka melihatnya". "Ya," jawab aku. Lalu 
beliau menegakkan saya dibelakangnya, pipi saya bersentuh dengan pipi beliau sambil beliau bersabda: "Teruskan hai anak Arfadah, sehingga bila saya telah bosan." Rasulullah bersabda: "Cukup?" "Ya," jawab aku. "Pergilah," sabda beliau."

Melihat hadits dan pendapat ulama' Fiqh secara nyata dapat dilihat bahwa figh memandang tarian adalah suatu yang alamiah dan dapat dilakukan oleh siapapun. Terutama dari pakaian yang dikenakan penari agar tidak mengundang syahwat bagi penonton. Perkembangan tari yang bisa dilihat dari perkembangan pakaian yang dikenakan penari lebih tertutup sehingga lebih sopan dan tidak akan menimbulkan masalah. Pandangan 4 mazhab yang banyak diikuti oleh sebagian besar kaum muslimin dunia yakni Imam Syafi'I, Imam Maliki, Imam Hanbali, dan Imam Hanafi memiliki kesepakatan bahwa muslim dalam berpakaian memiliki ketentuan dapat menutup aurat. Bahkan dapat dikatan bahwa menutup aurat hukumnya wajib dalam Islam.

Menutup aurat dalam pandangan Islam bukan tanpa alasan melainkan memiliki tujuan utama untuk menjalankan perintah Allah dan Nabi Muhammad Saw, menjaga diri dari perbuatan fitnah, melindungi diri dari hawa nafsu orang lain, mendapat ketenangan dan ketentraman jiwa serta sesuai dengan norma yang ada di masyarakat. ${ }^{13}$ Tari Tayub sebagai bagian dari seni tari merupakan bentuk aktualisasi ekspresi manusia. ${ }^{14}$ Akan tetapi hal penting yang perlu diperhatikan adalah pandangan seni dalam Islam juga harus mengajarkan nilai moral dan kebaikan. ${ }^{15}$

Melihat pendapat 4 madzab, hadits dan pandangan Islam terhadap seni dapat dinyatakan bahwa tari tayub bukan hal yang diharamkan akan tetapi dengan beberapa persyaratan utama berkaitan dengan tarian yang dilakukan tidak melanggar ajaran agama dan tidak menimbulkan keresahan di masyarakat. Melihat tarian tayub dalam perspektif figh tentu dapat dipahami bahwa tarian tayub ini bagian perasaan dan ungkapan kebahagiaan yang diluapkan masyarakat karena berkah panen dan rizqi yang melimpah. After the Indonesian people recognized Islam and more and more people embraced this religion, Islamic law became a living law in society. ${ }^{16} \mathrm{Hal}$ ini dapat

\footnotetext{
${ }^{13}$ Livia Setyawati, Budaya Tari Lengger Dalam Perspektif Hukum Islam di Kabupaten Wonosobo, Jurnal AlMada Volume 4, No.1, 2021, hlm.74

14 Tri Yuliana Wijayanti, Seni Tari Dalam Pandangan Islam, Jurnal Alfuad Volume 2, nomer 2, 2018, hlm.54

${ }^{15}$ Khoirul Anwar et al., "Ka'b Al-Ahbar: Founder of the Transformation Jewish Tradition to Islam," 2021, 17-19, https://doi.org/10.4108/eai.14-10-2020.2303851.

${ }^{16}$ Abu Rokhmad, "Institutions and Contributions to Islamic Law in Indonesia's Legal System"Walisongo Law Review (Walrev), volume 3 Nomer 1(2021), hlm.22
} 
dipahami bahwa agama Islam telah menjadi acuan atau hukum bagi kehidupan bermasyarakat, sehingga pemahaman 4 madzab maupun hadits tersebut cukup relevan bila dikaitkan dengan kajian tari tayub. Tidak ada unsur pornografi dan porno aksi dalam penyelenggaraan tarian Tayub dengan demikian dalam perspektif fiqh budaya tarian tayub bukan hal yang dilarang atau diharamkan agama karena selain sebagai bentuk ekspresi kebahagiaan juga sebagai bentuk kecintaan terhadap adat istiadat dan kebiasaan masyarakat.

\section{Simpulan}

Berdasarkann hasil penelitian dan pembahasan simpulan dalam penelitian ini adalah tradisi sedekah bumi di desa Plaosan merupakan tradisi turun temurun yang dilaksanakan sebagai wujud rasa syukur kepada Tuhan YME. Tradisi sedekah bumi memegang peranan penting dalam masyarakat petani karena dilaksanakan dengan harapan hasil panen melimpah dan memberikan kesejahteraan bagi masyrakat. Pelaksanaan tradisi sedekah bumi diawali dengan tahap persiapan yakni pembentukan panitia sedekah bumi. Panitia sedekah bumi memastikan kegiatan dapat terlaksana dengan baik dan sesuai harapan semua masyarakat. Dalam pelaksanaan tradisi sedekah bumi semua masyarakat terlibat dan ikut andil dalam setiap prosesi sedekah bumi. Rangkaian kegiatan tradisi sedekah bumi yakni prosesi selametan, manganan di punden, arak-arakan ancak, pertunjukkan ketoprak dan juga pertunjukkan tarian tayub sebagai syarat utama dalam terlaksananya sedekah bumi. Kajian Fiqh Budaya dalam Tarian Tayub pada dasarnya melihat bagian penting bahwa tradisi menari bukanlah hal yang dilarang oleh agama Islam. Dengan demikian boleh dilakukan karena tidak bertentangan dengan syariat agama.

\section{Daftar Pustaka}

Adzkiya, Ubbadul, and Anas Rohman. "Sacred Values Of Cows I n Kudus Society's View" 140, no. ISCoGI 2017 (2019): 72-75.

anggun sisweda. "NILAI PENDIDIKAN ISLAM DALAM TRADISI SEDEKAH BUMI (Studi

Kasus Di Dusun Melati Desa Olak-Olak Kubu Kecamatan Kubu Kabupaten Kubu Raya Tahun 2019)." JRTIE 3 (2020).

Anwar, Khoirul, Abu Hapsin, Nazar Nurdin, Ubbadul Adzkiya, Iman Fadhilah, and Tedi Kholiludin. "Ka'b Al-Ahbar: Founder of the Transformation Jewish Tradition to 
Islam," 2021, 17-19. https://doi.org/10.4108/eai.14-10-2020.2303851.

fitria martanti. "EVALUASI IMPLEMENTASI PROGRAM PENGEMBANGAN USAHA

AGRIBISNIS PERDESAAN SEBAGAI UPAYA PEMBERDAYAAN MASYARAKAT

MISKIN." Journal of Economic Education 1 (2012).

—. "INTERGRATION OF ASWAJA TEACHING: CONCEPT OF STRENGTHENING CHARACTER EDUCATION IN COLLEGE," n.d.

Huda, Mohammad Thoriqul. "Harmoni Sosial Dalam Tradisi Sedekah Bumi Masyarakat Desa Pancur Bojonegoro." Religio 7 (2017): 267-96.

_. "Harmoni Sosial Dalam Tradisi Sedekah Bumi Masyarakat Desa Pancur Bojonegoro." Religió: Jurnal Studi Agama-Agama 7, no. 2 (2017).

https://doi.org/10.15642/religio.v7i2.753.

Martanti, Fitria. "PERAN FURU KELAS DALAM MEMBERIKAN LAYANAN BIMBINGAN DAN KONSELING DI SDN WATUAJ 01 KABUPATEN JEPARA." Magistra 6 (2015). Pinihanti, Sabty -. "PENANAMAN RASA SYUKUR MELALUI TRADISI SEDEKAH BUMI DI DESA TEGALARUM, DEMAK: KAJIAN INDIGENOUS PSIKOLOGI." Dinamika Sosial Budaya 22 (2020).

R. Atang Supriatna. "MENGUAK REALITAS PRAKTIK SEDEKAH BUMI DI DESA CIASMARA KECAMATAN PAMIJAHAN KABUPATEN BOGOR." Wahana 2 (2020). suharji. "TARI TAYUB SEBAGAI SARANA UPACARA RITUAL DI DESA WONOSOCO KECAMATAN UNDAAN KUDUS." Acintya 6 (2017). 